\title{
ANALISIS KONJOIN UNTUK MENGUKUR PREFERENSI KONSUMEN TERHADAP ATRIBUT KERTAS SENI DARI SABUT PINANG SIRIH (ARECA CATECHU L.) DAN KERTAS KORAN
}

\section{Conjoint Analysis to Measure Consumer Preferences on Atribut of Art Paper from Betel Nut Fiber (Areca catechu L.) and Newspaper}

\author{
Azimmatul Ihwah*, Haris Agus Saputra, Panji Deoranto, Ika Atsari Dewi, Nur Lailatul Rahmah \\ Jurusan Teknologi Industri Pertanian - Fakultas Teknologi Pertanian - Universitas Brawijaya \\ Jl. Veteran - Malang 65145 \\ *Penulis Korespondensi, email : azimmatul.ihwah@ub.ac.id
}

Disubmit: 5 Nopember 2020 Direvisi: 29 Januari 2020 Diterima: 10 Februari 2020

\begin{abstract}
ABSTRAK
Produk kertas seni dari sabut pinang sirih dan kertas koran merupakan salah satu produk baru. Salah satu cara untuk mengenalkan produk baru ke konsumen adalah dengan menampilkan atribut produk yang disukai konsumen sehingga dapat mempengaruhi pengambilan keputusan pembelian produk. Tujuan penelitian ini adalah untuk mengetahui tingkat preferensi konsumen dan mengetahui kombinasi atribut produk kertas seni dari sabut pinang sirih dan kertas koran yang paling disukai konsumen. Penelitian ini merupakan penelitian korelasional, yaitu untuk mengetahui hubungan dari atribut yang diteliti. Pada penelitian ini menggunakan analisis konjoin dengan 7 atribut yaitu kekakuan, kuat tarik, ketebalan, gramatur, warna, kenampakan serat, dan tekstur permukaan. Berdasarkan penelitian yang telah dilakukan, diketahui bahwa atribut yang dipentingkan konsumen secara berturut-turut adalah kenampakan serat $(35,11 \%)$, gramatur $(16,85 \%)$, tekstur permukaan $(14,89 \%)$, kuat tarik $(13,20 \%)$, warna $(9,55 \%)$, kekakuan $(6,18 \%)$, dan ketebalan $(4,21 \%)$. Hasil yang sesuai dengan preferensi konsumen yaitu pada stimuli 6 dengan nilai kegunaan total sebesar 3,619. Kombinasi atribut yang disukai konsumen adalah kekakuan lentur $(97,825 \mathrm{mN} . \mathrm{m})$, kuat tarik kuat $\left(15,621 \mathrm{kn} / \mathrm{m}^{2}\right)$, ketebalan tipis $(1,325 \mathrm{~mm})$, gramatur rendah $\left(365 \mathrm{~g} / \mathrm{m}^{2}\right)$, warna abu-abu tua, kenampakan serat terlihat jelas, dan tekstur permukaan halus.
\end{abstract}

Kata Kunci: Kertas Seni; Konjoin; Pinang; Preferensi Konsumen

\section{ABSTRACT}

The products of art paper from betel nut and newspapers are one of new products. One way to introduce new products to consumers is to display product attributes that consumers like so that they can influence product purchase decisions. The purpose of this research was to determine the level of consumer preference and find out combination of attributes of art paper products from betel nut and newspapers that are most preferred by consumers. This research is a correlational research, which is to determine relationship between the attributes researched. In this research using conjoint analysis with 7 attributes, namely stiffness, tensile strength, thickness, grammage, color, fiber appearance, and surface texture. Based on the research that has been done, it is known that the attributes that are important to consumers in a row are fiber appearance $(35.11 \%)$, grammage $(16.85 \%)$, surface texture $(14.89 \%)$, tensile strength $(13.20 \%)$, color $(9.55 \%)$, stiffness $(6.18 \%)$, and thickness $(4.21 \%)$. The results are by following with consumer preferences, namely on stimuli 6 with total usefulness of 3,619. The combination of attributes that consumers like is flexural stiffness $(97.825 \mathrm{mN} . \mathrm{m})$, strong tensile strength $(15.621 \mathrm{kn} / \mathrm{m} 2)$, thin thickness $(1,325 \mathrm{~mm})$, low grammage $(365 \mathrm{~g} / \mathrm{m} 2)$, dark gray, visible fiber appearance clear, and smooth surface texture.

Keywords: Art Paper; Betel Nut; Conjoint; Consumer Preferences 


\section{PENDAHULUAN}

Pinang sirih tumbuh banyak di daerah tropis seperti Asia dan sebagian Asia Timur. Berdasarkan data Badan Pusat Statistika (2018) produksi biji pinang di Indonesia mengalami peningkatan yaitu pada 2012 (42.000 ton), 2013 (42.850 ton), 2014 (47.000 ton), dan 2015 (47.100 ton). Bagian dari pinang sirih yang banyak dimanfaatkan adalah bijinya, semen-tara sabut pinang sirih kurang dimanfaatkan dengan baik. Salah satu pemanfaatannya ada-lah sebagai bahan baku dalam pembuatan kertas seni. Menurut Vitaloka et al., (2017) kertas seni dibuat secara manual menggu-nakan tangan (handmade) sehingga dihasilkan produk akhir yang secara visual memiliki karakter spesifik dari segi bentuk, tekstur, warna, dan corak. Untuk mendapatkan kertas seni dengan kualitas yang baik maka perlu adanya bahan tambahan lain seperti kertas koran. Khrisna dan Andereas (2017) menya-takan bahwa kertas koran mengandung pulp mekanis sebesar $80-85 \%$ dan pulp kimia $15-20 \%$ yang berguna untuk meningkatkan ke-kuatan kertas.

Salah satu cara untuk mengenalkan produk baru ke konsumen adalah dengan menampilkan atribut produk yang disukai konsumen sehingga dapat mempengaruhi pengambilan keputusan pembelian produk. Kertas seni dari sabut pinang sirih dan kertas koran dapat menjadi inovasi baru sebagai bahan baku dalam pembuatan paper bag yang dapat memberikan kesan vintage.

Dalam menganalisis aspek pasar dibutuhkan analisis preferensi konsumen terha-dap produk yang akan dihasilkan. Preferensi konsumen merupakan sikap untuk menge-tahui suka atau tidaknya seorang konsumen terhadap suatu barang atau jasa. Oleh karena itu perlu adanya kombinasi atribut yang akan membentuk sikap konsumen terhadap suatu produk dan mempengaruhi keputusan pem-belian konsumen (Tinaprilia, 2007). Menurut Dadang dan Putri (20114) Preferensi konsumen muncul pada tahap evaluasi alternatif dalam proses keputusan pembelian.

Salah satu cara untuk menentukan pre-ferensi konsumen dapat dilakukan dengan analisis konjoin. Analisis konjoin merupakan teknk multivariat yang berguna untuk me-nentukan sifat konsumen dalam menentukan preferensi terhadap suatu produk atau jasa (Schaupp dan Belanger, 2005). Menurut Hair et al., (2010) dengan menilai objek yang dibentuk berdasarkan kombinasi atribut maka konsumen dapat memberikan perkiraan pre-ferensi. Dengan demikian perusahaan dapat mendesain kombinasi atribut yang disukai konsumen dan menghilangkan atribut yang relatif kurang disukai konsumen.

\section{METODE}

Penelitian dilakukan di kota Malang, Jawa Timur pada bulan Januari hingga Mei 2019. Pembuatan sampel produk dilakukan di Laboratorium Teknologi Agrokimia, TIPFTP-UB. Analisis data dilakukan di Laboratorium Manajemen Agroindustri, TIP-FTP-UB.

Penentuan batasan masalah dilakukan untuk menyederhanakan ruang lingkup ma-salah pada penelitian. Adapun batasan ma-salah pada penelitian ini adalah objek pene-litian ini hanya difokuskan pada masyarakat di kota Malang, hanya menggunakan 7 atribut yang berupa bauran atribut fisik (ke-kakuan, kuat tarik, ketebalan, dan gramatur) dan bauran atribut organoleptik (warna, ke-nampakan serat, dan tekstur permukaan), responden dianggap dapat membedakan komponen atribut produk kertas seni, dan produk merupakan inovasi produk baru tanpa ada produk pembanding di pasaran.

Populasi yang digunakan pada penelitian ini adalah masyarakat di kota Malang, sedangkan sampel yang digunakan adalah masyarakat yang pernah menggunakan paper bag. Teknik sampling yang digunakan yaitu teknik non probability sampling yang berupa purposive sampling. Penentuan sampel didasar-kan pada kriteria yang telah ditentukan. Ada-pun kriteria responden yang dipilih adalah berusia 1755 tahun (usia produktif) dan pernah menggunakan paper bag dalam 3 bulan terakhir. Penelitian ini merupakan penelitian korelasional, yaitu untuk mengetahui hu-bungan dari atribut yang diteliti. Pada penelitian ini menggunakan 
50 responden karena untuk memenuhi batas minimal penelitian korelasional dan analisis konjoin. Menurut Alwi (2015) minimal sampel penelitian korelasional ada-lah 30 responden. Menurut Hair et al., (2010) untuk mendapatkan preferensi konsumend dapat menggunakan ukuran sampel minimal 50 reponden.

Metode pengumpulan data dilakukan dengan wawancara dan kuesioner. Wawancara dilakukan untuk mendapatkan informasi dari responden terhadap permasalahan yang ada. Pada penelitian ini wawancara dilakukan untuk mendapatkan responden yang sesuai dengan karakteristik yang dibutuhkan. Penye-baran Kuesioner dilakukan untuk menda-patkan data dari responden yang dibutuhkan pada penelitian dan selanjutnya dilakukan pengolahan dan analisis data. Kuesioner pada penelitian ini berupa pertanyaan tertutup dngan menggunakan skala likert dengan stor 1 sampai 5 .

\section{Penentuan Atribut Penelitian}

Penentuan atribut dilakukan untuk mengetahui karakteristik dari produk yang akan diteliti. Pada penelitian ini menggunakan 2 bauran atribut yang diuraikan menjadi 7 atribut dan 14 taraf.

Tabel 1. Rancangan atribut dan taraf penelitian

\begin{tabular}{|c|c|c|}
\hline Bauran & Atribut & Taraf \\
\hline \multirow[t]{8}{*}{ Fisik } & Kekakuan & Kaku \\
\hline & & Lentur \\
\hline & Kuat Tarik & Kuat \\
\hline & & Lemah \\
\hline & Ketebalan & Tebal \\
\hline & & Tipis \\
\hline & Gramatur & Tinggi \\
\hline & & Rendah \\
\hline \multirow{6}{*}{$\begin{array}{l}\text { Organo } \\
\text { leptik }\end{array}$} & Warna & Abu-Abu Muda \\
\hline & & Abu-Abu Tua \\
\hline & Kenampakan & Terlihat Jelas \\
\hline & Serat & $\begin{array}{l}\text { Tidak Terlihat } \\
\text { Jelas }\end{array}$ \\
\hline & Tekstur & Halus \\
\hline & Permukaan & Kasar \\
\hline
\end{tabular}

\section{Uji Validitas dan Reliabilitas}

Uji validitas dan reliabilitas dilakukan pada data yang telah didapatkan dari kuesioner. Uji validitas dilakukan untuk mengetahui ketepatan alat ukur yang digunakan dapat mengukur variabel yang akan dikur (Taherdoost, 2016). Menurut Widi (2011) variabel dapat dikatakan valid apabila bernilai positif, dimana sig $<0,05$. Menurut Solimun et al., (2017) uji reliabilitas dilakukan untuk mengetahui sejauh mana tingkat konsistensi pengukuran pada data yang telah didapatkan, dimana variabel dapat dikatakan reliabel apabila nilai Cronbach's Alpha $>60 \%$.

\section{Analisis Data}

1. Penentuan Kombinasi Atribut (Stimuli)

Penentuan stimuli pada penelitian ini dilakukan menggunakan pendekatan full profile yaitu dengan mengkombinasikan taraf atribut secara lengkap. Stimuli yang didapatkan berdasarkan jumlah taraf yaitu 128. Hal tersebut terlalu banyak dan menyebabkan responden tidak konsisten dalam memberikan penilaian sehingga direduksi menggunakan prosedur orthogonal design. Holdout yang digunakan pada prosedur orthogonal design $=4$ untuk mewakili stimuli yang telah direduksi dan mendapatkan tingkat akurasi lebih tinggi karena dapat memprediksi keanggotaan $100 \%$, sehingga didapatkan total 12 stimuli.

\section{Penentuan Variabel Dummy}

Variabel dummy digunakan untuk merubah variabel kualitatif menjadi kuantitatif untuk mempermudah dalam pengolahan data yang dinyatakan dengan nilai 0 dan 1 (Usman et al., 2015). Apabila atribut mempunyai taraf sebanyak $n$, maka jumlah variabel dummy pada setiap atribut adalah n-1. Variabel dummy pada penelitian ini sebanyak 7 (X1 sampai X7). X1 untuk atribut kekakuan, $\mathrm{X} 2$ untuk atribut kuat tarik, X3 untuk atribut ketebalan, X4 untuk atribut gramatur, $X 5$ untuk atribut warna, X6 untuk atribut kenampakan serat, dan X7 untuk atribut tekstur permukaan. 
Jurnal Teknologi Pertanian Vol. 21 No. 1 [April 2020] 39-48

Analisis Konjoin untuk Mengukur Preferensi Konsumen [Ihwah dkk]

Tabel 2. Kombinasi atribut produk (stimuli)

\begin{tabular}{|c|c|c|c|c|c|c|c|}
\hline No & Kekakuan & $\begin{array}{l}\text { Kuat } \\
\text { Tarik }\end{array}$ & Ketebalan & Gramatur & Warna & Kenampakan Serat & $\begin{array}{c}\text { Tekstur } \\
\text { Permu- } \\
\text { kaan }\end{array}$ \\
\hline 1. & Lentur & Kuat & Tebal & Rendah & Abu-abu Tua & $\begin{array}{l}\text { Tidak Terlihat } \\
\text { Jelas }\end{array}$ & Halus \\
\hline 2. & Kaku & Lemah & Tipis & Tinggi & Abu-abu Tua & Terlihat Jelas & Kasar \\
\hline 3. & Lentur & Kuat & Tipis & Tinggi & Abu-abu Tua & Terlihat Jelas & Kasar \\
\hline 4. & Kaku & Kuat & Tipis & Rendah & $\begin{array}{l}\text { Abu-abu } \\
\text { Muda }\end{array}$ & $\begin{array}{l}\text { Tidak Terlihat } \\
\text { Jelas }\end{array}$ & Kasar \\
\hline 5. & Kaku & Lemah & Tebal & Rendah & Abu-abu Tua & Terlihat Jelas & Kasar \\
\hline 6. & Lentur & Kuat & Tipis & Rendah & Abu-abu Tua & Terlihat Jelas & Halus \\
\hline 7. & Kaku & Kuat & Tebal & Tinggi & $\begin{array}{l}\text { Abu-abu } \\
\text { Muda }\end{array}$ & Terlihat Jelas & Halus \\
\hline 8. & Lentur & Lemah & Tebal & Tinggi & $\begin{array}{l}\text { Abu-abu } \\
\text { Muda }\end{array}$ & $\begin{array}{l}\text { Tidak Terlihat } \\
\text { Jelas }\end{array}$ & Kasar \\
\hline 9. & Lentur & Lemah & Tipis & Rendah & $\begin{array}{l}\text { Abu-abu } \\
\text { Muda }\end{array}$ & Terlihat Jelas & Halus \\
\hline 10. & Lentur & Kuat & Tebal & Tinggi & Abu-abu Tua & $\begin{array}{l}\text { Tidak Terlihat } \\
\text { Jelas }\end{array}$ & Kasar \\
\hline 11. & Kaku & Lemah & Tipis & Tinggi & Abu-abu Tua & $\begin{array}{l}\text { Tidak Terlihat } \\
\text { Jelas }\end{array}$ & Halus \\
\hline 12. & Lentur & Kuat & Tebal & Tinggi & Abu-abu Tua & $\begin{array}{l}\text { Tidak Terlihat } \\
\text { Jelas }\end{array}$ & Halus \\
\hline
\end{tabular}

Tabel 3. Variabel dummy berdasarkan stimuli

\begin{tabular}{cccccccc}
\hline Stimuli & $\mathrm{X}_{1}$ & $\mathrm{X}_{2}$ & $\mathrm{X}_{3}$ & $\mathrm{X}_{4}$ & $\mathrm{X}_{5}$ & $\mathrm{X}_{6}$ & $\mathrm{X}_{7}$ \\
\hline 1 & 0 & 1 & 1 & 0 & 0 & 0 & 1 \\
2 & 1 & 0 & 0 & 1 & 0 & 1 & 0 \\
3 & 0 & 1 & 0 & 1 & 0 & 1 & 0 \\
4 & 1 & 1 & 0 & 0 & 1 & 0 & 0 \\
5 & 1 & 0 & 1 & 0 & 0 & 1 & 0 \\
6 & 0 & 1 & 0 & 0 & 0 & 1 & 1 \\
7 & 1 & 1 & 1 & 1 & 1 & 1 & 1 \\
8 & 0 & 0 & 1 & 1 & 1 & 0 & 0 \\
9 & 0 & 0 & 0 & 0 & 1 & 1 & 1 \\
10 & 0 & 1 & 1 & 1 & 0 & 0 & 0 \\
11 & 1 & 0 & 0 & 1 & 0 & 0 & 1 \\
12 & 0 & 1 & 1 & 1 & 0 & 0 & 1 \\
\hline
\end{tabular}

Perhitungan regresi

Nilai regresi berguna untuk memprediksi nilai kegunaan taraf. Perhitungan nilai regresi menggunakan variabel dummy yang dimodelkan dalam persamaan:

$U=b_{0}+b_{1} X_{1}+b_{2} X_{2}+b_{3} X_{3}+b_{4} X_{4}+b_{5} X_{5}+b_{6} X_{6}+$ $b_{7} X_{7}$

3. Perhitungan nilai kegunaan taraf

Nilai kegunaan taraf digunakan untuk menunjukkan taraf yang paling disukai konsumen pada suatu atribut (Santoso, 2012). Perhitungan dapat dilakukan berdasarkan nilai koefisien regresi menggunakan persamaan:

$$
\begin{aligned}
& \infty_{\mathrm{ij}-} \infty_{\mathrm{ij}}=\mathrm{b}_{\mathrm{i}} \\
& \infty_{\mathrm{ij}}+\infty_{\mathrm{ij}}=0 \\
& \infty_{\mathrm{ij}}=\text { nilai kegunaan (atribut ke-i level ke-j) } \\
& \text { pada tiap atribut. }
\end{aligned}
$$


4. Perhitungan tingkat kepentingan atribut

Perhitungan tingkat kepentingan atribut dilakukan berdasarkan hasil perhitungan nilai kegunaan taraf menggunakan rumus:

$$
I_{i}=\infty_{\mathrm{ij}} \max -\infty_{\mathrm{ij}} \min
$$

Untuk mengetahui bobot kepentingan relatif dilakukan perhitungan menggunakan rumus:

$$
\mathrm{W}_{\mathrm{i}}=\frac{I i}{\sum_{i=1}^{m} I i} \times 100 \%
$$

5. Perhitungan nilai kegunaan total stimuli

Nilai kegunaan total stimuli diperoleh dengan mencari konstanta dari total rata-rata stimuli. Konstanta yang diperoleh kemudian digunakan untuk membuat persamaan dasar konjoin dengn cara dijumlahkan dengan nilai kegunaan taraf. Perhitungan nilai kegunaan total stimuli dapat dicari menggunakan rumus:

$\mu(x)=\infty_{0}+\sum_{i=1}^{m} \sum_{j=1}^{k} \infty_{\mathrm{ij}} . \mathrm{X}_{\mathrm{ij}}$

$\mathrm{X}_{\mathrm{ij}}=$ variabel dummy atribut ke-I taraf ke-j.

\section{HASIL DAN PEMBAHASAN}

\section{Gambaran Umum Responden}

Berdasarkan penyebaran kuesioner yang dilakukan kepada 50 responden, dapat diketahui responden banyak didominasi oleh usia 17-25 tahun, jenis kelamin perempuan, bekerja sebagai pelajar/mahasiswa. Berdasarkan karakteristik responden dapat diketahui bahwa konsumsi paper bag dalam 3 bulan terkhir cukup tinggi. Sebagian besar responden banyak mendapatkan paper bag dari souvenir dari acara/tempat belanja/pembungkus kado. Selain itu, sebagian besar responden telah mengetahui kertas seni tetapi belum mengetahui pemanfaatan kertas seni sebagai paper bag. Responden juga telah mengetahui pinang sirih tetapi belum mengetahui pemanfaatan pinang sirih sebagai kertas seni.

\section{Uji Validitas dan Reliabilitas}

Uji validitas dan reliabilitas dilakuakan pada 14 taraf yang telah diberikan penilaian oleh responden. Tingkat signifikansi yang digunakan sebesar 95\% sehingga didapatkan a sebesar 5\%. Berdasarkan uji validitas, keseluruhan data pada penelitian ini dikatakan valid karena nilai sig yang dihasilkan $<0,05$ sehingga kuesioner penelitian akurat dan dapat mengukur secara tepat. Berdasarkan uji reliabilitas dihasilkan nilai cronbach's Alpa sebesar 0,602 yang berarti reliabel sehingga jawaban responden pada penelitian ini konsisten dan kuesioner dapat dikatakan sebagai alat ukur yang baik dan dapat dipercaya.

\section{Regresi Linear}

Berdasarkan regresi linear didapatkan nilai $\mathrm{R}$ square sebesar 0,945 sehingga preferensi konsumen dipengaruhi oleh 94,5\% atribut yang digunakan. Nilai sig yang didapatkan sebesar 0,022 yang menunjukkan atribut dapat mewakili preferensi konsumen. Nilai regresi yang didapatakan dapat disubstitusi ke dalam persamaan:

$Y=3,528-0,022 X_{1}+0,047 X_{2}-0,015 X_{3}-$ $0,060 X_{4}+0,034 X_{5}+0,125 X_{6}-0,053 X_{7}$

Variabel Y merupakan variabel terikat yang berupa preferensi konsumen dan variabel $\mathrm{X}$ merupakan variabel bebas yang berupa atribut yang digunakan pada penelitian ini.

\section{Nilai Kegunaan Taraf}

Nilai kegunaan taraf didapatkan dari perhitungan koefisien regresi. Perhitungan nilai kegunaan menghasilkan taraf yang bernilai positif dan negatif, dimana nilai terbesar menunjukkan taraf yang sesuai dengan preferensi konsumen.

Pada atribut kekakuan menunjukkan bahwa kekakuan lentur paling disukai konsumen. Konsumen menyukai kekakuan lentur karena kertas seni sebagai bahan dasar pembuatan paper bag membutuhkan kertas yang lentur sehingga mudah untuk dibentuk. Apabila kertas yang digunakan terlalu kaku maka ketika dibentuk menjadi paper bag akan mudah sobek. Sebenarnya pada masing-masing kertas memiliki standar kekakuan tersendiri tergantung pemanfaatan kertas tersebut. Julianti (2014) menyatakan bahwa kertas yang digunakan untuk pengemas, kekakuan dan arah serat kertas harus diperhatikan karena akan mempengaruhi efisiensi dari mesin pengemas. 
Jurnal Teknologi Pertanian Vol. 21 No. 1 [April 2020] 39-48

Analisis Konjoin untuk Mengukur Preferensi Konsumen [Ihwah dkk]

Tabel 4. Nilai kegunaan taraf

\begin{tabular}{llc}
\hline \multicolumn{1}{c}{ Atribut } & \multicolumn{1}{c}{ Taraf } & $\begin{array}{c}\text { Nilai } \\
\text { Kegunaan }\end{array}$ \\
\cline { 3 - 3 } Kekakuan & Kaku & $-0,011$ \\
& Lentur & $0,011^{*}$ \\
Kuat Tarik & Kuat & $0,0235^{*}$ \\
& Lemah & $-0,0235$ \\
Ketebalan & Tebal & $-0,0075$ \\
& Tipis & $0,0075^{*}$ \\
Gramatur & Tinggi & $-0,03$ \\
& Rendah & $0,03^{*}$ \\
& Abu-Abu & 0,017 \\
& Muda & \\
Kenampakan & Abu-Abu & $-0,017^{*}$ \\
Serat & Tua & \\
& Jerlihat & $0,0625^{*}$ \\
& Tidak & $-0,0625$ \\
Tekstur & Terlihat & \\
Permukaan & Jelas & \\
\hline & Kalus & $-0,0265$ \\
& Kasar & $0,0265^{*}$ \\
\hline
\end{tabular}

Pada atribut kuat tarik menunjukkan bahwa kuat tarik kuat paling disukai konsumen. Kuat tarik yang kuat pada kertas seni akan menjadi nilai tambah dalam segi kualitas. Kertas seni pada penelitian ini nantinya akan digunakan sebagai paper bag sehingga membutuhkan kualitas yang sesuai. Terlebih paper bag biasanya digunakan sebagai tempat/wadah suatu barang. Apabila paper bag terbuat dari kertas dengan kuat tarik yang lemah maka mempengaruhi tingkat kerapuhan pada kertas sehingga akan mudah sobek dan jebol. Menurut Asngad et al., (2016) panjang dan ikatan serat yang terbentuk da-pat mempengaruhi kuat tarik, dimana se-makin tinggi kekuatan ikatan antar serat maka ketahanan tarik juga tinggi.

Pada atribut ketebalan menunjukkan bahwa ketebalan tipis paling disukai konsumen. Ketebalan yang tipis lebih disukai konsumen karena lebih fleksibel untuk dilipat menjadi paper bag dibandingkan kertas yang tebal. Yahandoyo (2001) memaparkan bahwa tebal atau tipisnya kertas dapat dipengaruhi oleh total berat dari pulp yang digunakan.

Pada atribut gramatur menunjukkan bahwa gramatur rendah paling disukai konsumen. Gramatur rendah lebih disukai konsumen karena kertas seni yang digunakan sebagai paper bag membutuhkan berat yang ringan agar mudah pada saat dibawa. Gramatur berhubungan dengan ketebalan dan kekakuan, sehingga apabila kertas memiliki gramatur rendah maka kertas juga kaku dan cenderung lebih tipis. Menurut Vitaloka et al., (2017) gramatur dapat dipengaruhi oleh proses pengepresan pada alat pencetak yang digunakan, dimana semakin kuat pengepresan maka akan mengurangi rongga yang ada didalam kertas sehingga dihasilkan gramatur juga akan rendah.

Pada atribut warna menunjukkan bahwa warna abu-abu muda lebih disukai konsumen. Warna abu-abu muda lebih disukai konsumen karena warna yang dihasilkan lebih cerah. Warna abu-abu muda telah melalui proses bleaching sehingga warna dari sabut pinang dan kertas koran yang dihasilkan terlihat berbeda dari warna aslinya. Warna abu-abu tua terlihat kurang menarik karena warna yang dihasilkan masih warna alami dari kertas koran sehingga terlihat lebih gelap. Pilihan responden tersebut tidak sesuai dengan trend vitage, dimana produk yang bertemakan vin-tage lebih mengutamakan sifat asli dan alami dari bahan baku sehingga produk akhir yang dihasilkan lebih terlihat natural.

Pada atribut kenampakan serat menunjukkan bahwa kenampakan serat terlihat jelas paling disukai konsumen. Kenampakan serat sudah menjadi ciri khas dari kertas seni karena menimbulkan kesan estetik. Konsumen memilih kenampakan serat yang terlihat jelas karena konsumen menyukai corak yang ditampilkan. Paper bag dari kertas seni terlihat lebih menarik dengan corak yang alami sehingga dapat menjadi daya tarik tersendiri.

Pada atribut tekstur permukaan menunjukkan bahwa tekstur permukaan kasar paling disukai konsumen. Tekstur permukaan berhubungan dengan kenampakan serat. Pada penelitian ini konsumen lebih menyukai kenampakan serat yang terlihat jelas sehingga tekstur permukaan yang dihasilkan juga kasar. Tekstur permukaan yang kasar ini menjadi ciri khas dari kertas seni karena adannya tektur alami dari serat tanaman. Pencetakan kertas pada penelitian ini dila-kukan secara manual dengan menggunakan screen sehingga tekstur pada permukaan ker-tas tidak rata.

\section{Tingkat Kepentingan Atribut}

Tingkat kepentingan atribut dapat dilihat pada Tabel 5. Berdasarkan tingkat kepentingan atribut, kenampakan serat memiliki nilai tertinggi yaitu $35,11 \%$ sehingga menjadi atri- 
but yang paling dipentingkan konsumen. Menurut Santoso (2012) tingkat kepentingan menunjukkan tingkat preferensi konsumen berdasarkan atribut yang paling dipentingkan konsumen dibandingkan beberapa atribut lainnya.

Tabel 5. Tingkat kepentingan masing-masing atribut

\begin{tabular}{lc}
\hline \multicolumn{1}{c}{ Atribut } & $\begin{array}{c}\text { Tingkat } \\
\text { Kepentingan (\%) }\end{array}$ \\
\cline { 3 - 3 } Kenampakan Serat & 35,11 \\
Gramatur & 16,85 \\
Tekstur Permukaan & 14,89 \\
Kuat Tarik & 13,20 \\
Warna & 9,55 \\
Kekakuan & 6,18 \\
Ketebalan & 4,21 \\
\hline
\end{tabular}

Alasan konsumen menjadikan kenampakan serat sebagai atribut yang paling dipentingkan karena kertas seni yang dihasilkan menampilkan serat-serat dari sabut pinang sirih sehigga menimbulkan kesan alami yang unik dan estetik. Adapun produk akhir dari kertas seni ini yaitu digunakan sebagai bahan pembuatan paper bag. Secara visual, paper bag dengan bahan kertas seni akan memberikan nilai seni tersendiri seperti vintage dan klasik karena terdapat motif tertentu yang ditampilkan dari adanya serat sabut pinang sirih. Apabila dihubungkan dengan karakteristik responden yang mengisi kuesioner penelitian ini, responden lebih mementingkan penampilan luar yang menjadi ciri khas dari kertas seni sehingga wajar apabila atribut lain kurang dipentingkan responden. Terlebih sebagian besar responden sebelumnya belum mengetahui kertas seni dari pinang sirih.

\section{Nilai Kegunaan Total Stimuli}

Preferensi konsumen terhadap masing-masing stimuli ditunjukan dengan nilai kegunaan total stimuli. Adapun persamaan dasar konjoin yang adalah sebagai berikut:

$\mu(X)=3,528-0,011 X_{11}+0,011 X_{12}+0,0235 X_{21}-$ $0,0235 X_{22}-0,0075 X_{31}+0,0075 X_{32}-0,03 X_{41}+$
$0,03 X_{42}+0,017 X_{51}-0,017 X_{52}+0,0625 X_{61}-$ $0,0625 X_{62}-0,0265 X_{71}+0,0265 X_{72}$

Dari persamaan dasar konjoin selanjutnya dilakukan perhitungan terhadap 12 stimuli untuk mengetahui urutan stimuli yang disukai hingga tidak disukai konsumen. Nilai kegunaan total stimuli diperoleh oleh stimuli 6 dengan nilai sebesar 3,619 dengan kombinasi atribut kekakuan lentur, kuat tarik kuat, ketebalan tipis, gramatur rendah, warna abu-abu tua, kenampakan serat terlihat jelas, dan tekstur permukaan halus.

Dari 12 nilai kegunaan total stimuli kemudian dirata-rata dan dihasilkan nilai 3,5261, dengan demikian dapat dikatakan bahwa secara umum responden "suka" terhadap kertas seni dari sabut pinang sirih dan kertas koran. Menurut Helmi et al., (2016) skala Likert dapat di interpretasikan dengan rentang penilaian $1,00-1,80$ sangat tidak suka, 1,81 - 2,60 tidak suka, 2,61 - 3,40 netral, 3,41 4,20 suka, dan 4,21 - 5,00 sangat suka. Hal tersebut mengindikasikan produk kertas seni yang dihasilkan secara umum dapat diterima oleh pasar dan berpotensi untuk dikembangkan dalam skala yang lebih besar.

\section{Validasi Hasil Anaalisis Konjoin}

Validasi analsisi konjoin ditunjukkan dengan nilai korelasi. Nilai korelasi kendall's tau pada penelitian ini sebesar 0.901. Hal tersebut menunjukkan bahwa nilai aktual dan nilai estimasi analisis konjoin memiliki korelasi yang kuat. Nilai maksimal antara korelasi nilai aktual dan nilai estimasi analisis konjoin yaitu sebesar 1. Pada penelitian ini korelasi yang dihasilkan tidak sepenuhnya bernilai $100 \%$. Hal tersebut disebabkan karena tidak semua stimuli digunakan karena telah direduksi pada saat pembentukan stimuli menggunakan prosedur orthogonal design. Menurut Julianisa et al., (2016) validasi hasil analisis konjoin dilakukan untuk mengetahui apakah hasil analisis konjoin dapat dikatakan agregat valid dalam memprediksi preferensi konsumen yang dapat dilakukan dengan penentuan koefisien kendall's tau. 


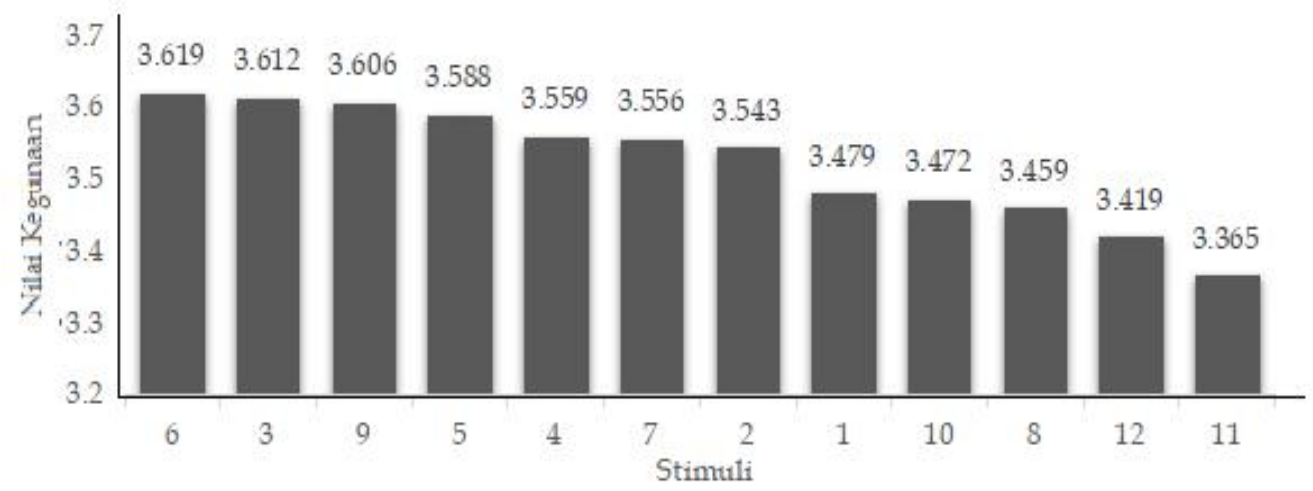

Gambar 1. Diagram batang nilai kegunaan masing-masing stimuli

Tabel 6. Hasil preferensi konsumen

\begin{tabular}{|c|c|c|c|}
\hline \multirow[b]{2}{*}{ Atribut } & \multicolumn{2}{|c|}{ Taraf } & \multirow[b]{2}{*}{$\begin{array}{l}\text { Hasil Pengujian } \\
\text { Produk }\end{array}$} \\
\hline & $\begin{array}{c}\text { Nilai Kegunaan } \\
\text { Taraf }\end{array}$ & $\begin{array}{c}\text { Nilai Kegunaan } \\
\text { Total Stimuli }\end{array}$ & \\
\hline Kekakuan & Lentur & Lentur & 97,825 mN.m \\
\hline Kuat Tarik & Kuat & Kuat & $15,621 \mathrm{kn} / \mathrm{m}^{2}$ \\
\hline Ketebalan & Tipis & Tipis & $1,325 \mathrm{~mm}$ \\
\hline Gramatur & Rendah & Rendah & $365 \mathrm{~g} / \mathrm{m}^{2}$ \\
\hline Warna & Abu-Abu Muda & Abu-Abu Tua & Abu-Abu Tua \\
\hline Kenampakan Serat & Terlihat Jelas & Terlihat Jelas & Terlihat Jelas \\
\hline Tekstur Permukaan & Kasar & Halus & Kasar \\
\hline
\end{tabular}

\section{Interpretasi Hasil}

Berdasarkan hasil yang didapatkan kemudian dilakukan pembuatan produk berdasarkan preferensi konsumen. Produk yang telah dibuat akan dilakukan pengujian untuk melihat kesesuaian antara preferensi konsumen dengan hasil produk akhir.

Berdasarkan hasil preferensi konsumen pada terdapat perbedaan antara nilai kegunaan total stimuli dengan nilai kegunaan taraf yang terletak pada atribut warna dan tekstur permukan. Hal tersebut dapat terjadi karena tidak semua stimuli utama digunakan dalam penelitian ini. Hasil dari penelitian ini didukung dengan nilai korelasi yaitu sebesar 0,901 $(90,1 \%)$ yang berarti bahwa korelasi antara nilai aktual dan nilai estimasi analisis konjoin tidak $100 \%$ karena dipangaruhi oleh faktor lain yang berupa atribut yang tidak digunakan pada penelitian seperti daya lipat, ketahanan sobek, dan daya jebol.

Pada hasil pengujian produk menunjukkan bahwa pada atribut tekstur permukaan memiliki perbedaan, dimana pada hasil preferensi konsumen diperoleh tekstur permukaan halus, sedangkan pada produk akhir diperoleh teksur permukaan kasar. Hal ter- sebut karena pada atribut kenampakan serat diperoleh kenampakan serat terlihat jelas, dimana kenampakan serat berbanding lurus dengan tekstur permukaan serat.

Pada produk kertas seni yang dihasilkan masih terdapat beberapa kekurangan yaitu dari segi daya serap air, ketahanan jebol, daya lipat, dan ketahanan sobek. Produk yang dihasilkan memiliki daya serap air yang tinggi sehingga menyebabkan kertas mudah jebol apabila terkena air. Hal tersebut disebabkan karena filler yang digunakan berupa kertas koran yang mudah untuk menyerap air sehingga perlu adanya filler tambahan agar memperkuat struktur kertas seni yang dihasilkan. Kertas seni yang dihasilkan apabila dilipat mengahasilkan struktur kertas yang rapuh pada beberapa bagian tertentu sehingga menyebabkan kertas mudah sobek. Hal tersebut disebabkan karena pada proses pengadukan bahan kurang tercampur merata dan pada proses pengepresan masih belum optimal sehingga terdapat rongga-rongga udara yang menyebabkan struktur kertas rapuh. Oleh karena itu sebelum produk di pasarkan harus melalui tahap perbaikan terlebih dahulu. 


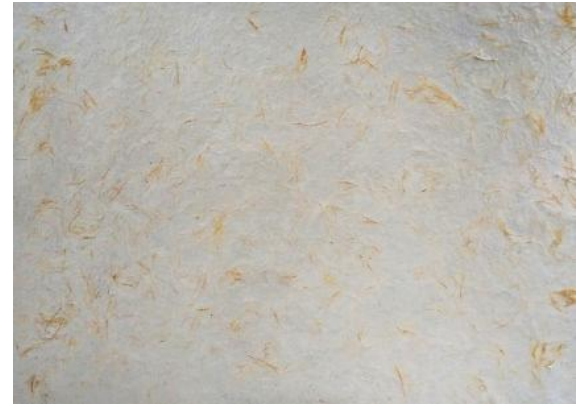

Gambar 2. Kertas seni hasil preferensi Konsumen

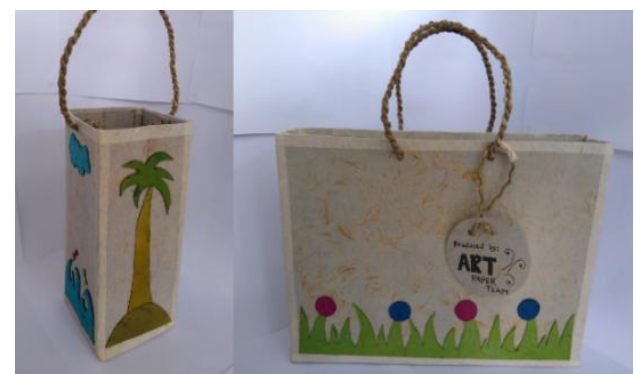

Gambar 3. Paper Bag dari Kertas Seni

\section{SIMPULAN}

Hasil penelitian diperoleh atribut yang dipentingkan konsumen secara berturut-turut adalah kenampakan serat dengan bobot kepentingan sebesar 35,11\%. Hasil preferensi konsumen yaitu pada stimuli 6 dengan nilai kegunaan total sebesar 3,619. Kombinasi atribut yang diperoleh adalah kekakuan lentur, kuat tarik kuat, ketebalan tipis, gramatur rendah, warna abu-abu tua, kenampakan serat terlihat jelas, dan tekstur permukaan halus. Saran untuk penelitian kedepan adalah perlu adanya atribut tambahan atribut tambahan agar dapat menyempurnakan atribut yang sudah ada seperti segi daya serap air, ketahanan jebol, daya lipat, dan ketahanan sobek. Selain itu perlu dilakukan perbandingan antara produk kertas seni yang dihasilkan dengan produk kertas seni yang sudah ada dipasaran agar dapat dilakukan penyesuaian standar mutu yang ada. Diharapkan terdapat penelitian lanjutan tentang analisis biaya produk kertas seni ini agar dapat dikomersialkan dalam skala besar.

\section{DAFTAR PUSTAKA}

Alwi, -I. 2015. Kriteria empirik dalam menentukan ukuran sampel pada pengujian hipotesis statistika dan analisis butir. Jurnal Formatif. 2(2), 140-148. http://dx. doi.org/10.30998/formatif.v2i2.95

Asngad, -A., Inna, -S.N., Suci, -S. 2016. Pemanfaatan kulit kacang dan bulu ayam sebagai bahan alternatif pem-buatan kertas melalui chemical pulping dengan menggunakan $\mathrm{NaOH}$ dan $\mathrm{CaO}$. Journal of Bioksperimen. 2(1), 25-34. https:

//doi.org/10.23917/bioeksperimen.v2i1. 1578

Badan Pusat Statistik. 2018. Produksi perkebunan rakyat menurut jenis tanaman (ribu ton), tahun 2000-2015. Dilihat pada 23 Mei 2019. <https://www.bps.go.id/ dynamictable/2018/06/21/1476/produk si-perkebunan-rakyat-menurut-jenistanaman-ribu-ton-2000-2017-.html>.

Hair, -J.F., Black, -W.C., Babin, -B.J., Anderson, -R.E. 2010. Multivariate data analysis seventh edition. Pearson Edition Inc. New Jersey.

Helmi, -T., Akhmad, -M., Irma, P. 2016. Kualitas pelayanan publik dalam pembuatan izin trayek oleh DLLAJ Kabupaten Bogor. Journal of Gonvernansi 2(1): 47-59. http:/ / dx.doi.org/10.30997/jgs.v2i 1.209

Julianisa, -R.D., Diah, -S., Hasbi, -Y. 2016. Analisis Konjoin Full Profile Dalam Pemilihan Bedak Untuk Mahasiswi Departemen Statistika Universitas Diponegoro. Journal of Gaussian 5(4): 747-756. http:/ / eprints.undip.ac.id/55043/1/Ros e_Debora.pdf

Julianti, -S. 2014. The Art of Packaging. Gramedia Pustaka Utama. Jakarta.

Khrisna, -V., Andereas, -P.S. 2017. Papan Partisi Dari Limbah Kertas. Jurnal Intra 5(2): 802-810. https:/ / media.neliti.com/ media/publications/98451-ID-papanpartisi-dari-limbah-kertas.pdf

Santoso, -S. 2012. Statistika Parametrik. PT. Gramedia Pustaka. Jakarta.

Schaupp, -L.C, Belanger, -F. 2005. A conjoint analysis of online consumer satisfaction. Journal of Electronic Commerce Research. 6(2), 95-111. https:/ / www.researchgate. net/publication/228358368_A_conjoint_a nalysis_of_online_consumer_satisfaction 
Jurnal Teknologi Pertanian Vol. 21 No. 1 [April 2020] 39-48

Analisis Konjoin untuk Mengukur Preferensi Konsumen [Ihwah dkk]

Solimun., Adji, -A.R.F., Nurjannah. 2017. Metode statistika multivariat. UB Press. Malang.

Taherdoost, -H. 2016. Validity and reliability of the research instrument; how to test the validation of a questionnaire/survey in a research. International Journal of Academic Research in Management and Bussiness. 5(3), 28-36. https:// doi.org/10. 2139/ssrn.3205040

Tinaprilla, -N. 2007. Jadi kaya dengan berbisnis di rumah: kiat praktis bagi wanita, mencapai kebebasan finansial tanpa harus meninggalkan keluarga. Elex Media Komputindo. Jakarta.
Vitaloka, -A., Rohanah, -A., Rindang, -A. 2017. Karakteristik kertas berbahan baku ampas tebu dan sampah kertas. Jurnal Rekayasa Pangan dan Pertanian. 5(1), 140144. https://jurnal.usu.ac.id/index.php/ jrpp/article/view/Adita\%20Vitaloka

Widi, -R. 2011. Uji validitas dan reliabilitas dalam penelitian epidemiologi kedokteran gigi. Jurnal Stomatognatic. 8(1), 27-34. https://jurnal.unej.ac.id/index.php/ STOMA/article/view/2083

Yahandoyo. 2001. Daur Ulang Kertas Untuk Hobi dan Bisnis. Kanisius. Yogyakarta. 